\title{
Ürolojik Cerrahilerde Venöz Tromboembolizm
}

\author{
Zülfü Sertkaya, Metin Öztürk
}

Haydarpaşa Numune Eğitim ve Araştırma Hastanesi, Üroloji Kliniği, İstanbul

\section{Giriş}

$\mathrm{V}$ enöz tromboembolizm (VTE) perioperatif ve postoperatif mortalite ve morbiditenin en sık önlenebilir sebeplerinden biridir. Hastane ölümleri arasında \%10 ile ilk sıralarda yer almaktadır (1). Venöz tromboembolizm prevelansı Amerika Birleşik Devletleri'nde incelenmiş ve yılda 5 milyon kişide derin ven trombozu ve bu hastaların yaklaşık 600 bininde pulmoner emboli olduğu görülmüştür (2). Venöz tromboembolizm önlenebilir olması, erken tanı ile mortalite ve morbiditeden korunabilmesi açısından klinisyen için önem arz eder. Profilaksinin yapılmayışı, tanı ve tedavide gecikme ve emboli sonrası morbidite, mortalite ve hastanede kalış süresi ile ilişkili bulunmuştur (3).

Ürolojik ameliyatların özellikle pelvik bölgede yapılması ve postoperatif dönemde hareketliliğin kısıtlanması VTE'e yatkınlığı artırmaktadır. Nitekim prostatektomi, sistektomi, nefrektomi ve inkontinans cerrahisi gibi birçok operasyon sonrası VTE serileri yayınlanmıştır (4-7).

\section{Ürolojik Cerrahi Sonrası Venöz Tromboembolizm}

Derin ven trombozu (DVT) ve pulmoner emboli (PE) insidansı profilaksi verilmeyen 1990 öncesi dönemde çok net olmamakla birlikte; farklı cerrahi tekniklerde değişik oranlarda bildirilmiştir. Örneğin ürolojik cerrahi işlemlerden en yüksek DVT ve PE riski \%37 oranı ile radikal sistektomi sonrasında görülmüştür. Bu oran invaziv beyin cerrahisi ameliyatlarında \%3.6 ve total kalça protezi ameliyatlarında \%3.1 olarak bildirilmiştir (8).

Günümüzde bu oranların profilaksi ve hastaların yakın takibi ile düştüğü görülmüştür. Tyson ve ark.'larının 2014'te yayınladıkları son çalışmada, 82.808 ürolojik girişim ve sonrasındaki 30 günlük takipleri incelendiğinde, \%0.8 oranında DVT ve \%0.4 oranında ise PE geliştiği bildirilmiştir. Ürolojik girişimler içerisinde \%4 oranında DVT ve \%2.8 oranındaki PE riski ile radikal sistektomi, risk açısından ilk sırada yer almaktadır. Laparoskopik kolpopeksi ise; DVT ve PE riski açısından son sırada bulunmaktadır (6).

Dyer ve ark.'larının çalışmasında ise 126.891 ürolojik cerrahi girişim yapılan hasta değerlendirilmiş ve 12 aylık takip sonrası VTE gelişme ihtimali \%0.66 olarak bildirilmiştir. Radikal sistektomi VTE açısından en yüksek riskli (\%2.86) girişim olarak bildirilirken, uretral dilatasyon en düşük riskli (\%0.23) girişim olarak rapor edilmiştir. Çalışmada maligni- te nedeniyle yapılan girişimlerde ve litotomi pozisyonuna kıyasla supin pozisyonda yapılan ameliyatlarda VTE gelişme ihtimalinin daha yüksek olduğu bildirilmiştir (8).

Kanserli hastalarda DVT ve spontan VTE olasılığı normal popülasyona göre sirasıyla 2.2 ve 3.2 kat daha yüksektir. Kemoterapi alan hastalarda ise bu oranın 6.5 kata kadar yükseldiği bildirilmiştir $(9,10)$. Bu artış kanser hastalarında sıkça görülen ileri yaş, immobilite, sigara öyküsü, kronik santral venöz kataterizasyon ve kemoterapötik ajanların etkisi gibi nedenlere bağlanabilir. Ayrıca kanserin vücutta pıhtılaşma sistemini etkileyecek bir takım değişiklikler yapmasının da; risk artışına katkıda bulunduğu bildirilmiştir (11).

\section{Radikal Sistektomi}

Mesane kanseri nedeniyle radikal sistektomi yapılan hastalar, ürolojik girişimler arasında DVT ve PE gelişmesi açısından en riskli grubu oluşturmaktadır. Profilaksinin yapılmadığ1 dönemlerde VTE görülme olasılığ1 \%3.7 ve \%6 olarak bildirilirken, profilaksinin yapıldığı günümüzde bu oran ancak \%2.8'e kadar gerilemiştir $(6,9,12)$.

Radikal sistektomide görülen bu yüksek risk; hasta yaşı, immobilite, kardiyopulmoner hastalıklar, kanser varlığı, genişletilmiş pelvik lenf nodu disseksiyonu yapılması, adjuvan-neoadjuvan kemoterapi alınması ve santral venöz katater varlığ 1 ile ilişkilendirilmiştir (13).

\section{Radikal Retropubik Prostatektomi}

Radikal retropubik prostatektomi (RRP) yapılan hastalarda görülen VTE ile ilgili birçok çalışma yayımlanmıştır. Eski çalışmalarda DVT görülme oranı \%6.9-12, PE görülme oranı ise \%2-2.7 olarak bildirilirken, son yıllarda yapılan çalışmalarda bu oran DVT için \%0.2-7.8, PE için \% 0-2.7 olarak bildirilmektedir (14-18).

\section{Radikal/Parsiyel Nefrektomi}

Venöz tromboembolizm gelişimi nefrektomi sonrasında da; görülebilmektedir. Nefrektominin böbrek kanseri nedeniyle yapılması VTE gelişme riskini \%2'ye kadar çıkarabilir. Benign hastalıklar nedeniyle yapilan nefrektomilerde bu oran \%0.4 olarak bildirilmiştir (8). Pettus ve ark.'ları 19892005 yilları arasında, radikal veya parsiyel nefrektomi yap1lan 2.208 hastada VTE gelişim oranını profilaksinin olmadığ 
dönemde $\% 1.5$, profilaksinin yapıldı $\breve{1} 1$ dönemde ise; \%0.6-0.9 olarak bildirmişlerdir (19). Bu nedenle günümüzde radikal nefrektomi yapılan hastalara, rutin olarak profilaksi önerilmektedir (13).

\section{Transüretral Cerrahiler}

Ürolojik girişimler içerisinde transüretral cerrahiler sonrasında DVT ve PE, düşük oranlarda görülür. Profilaksinin yapılmadığı dönemlerde yapılan bir çalışmada, TURP sonrasında \%0.4 oranında görüldüğü bildirilmiştir (20). Başka bir çalışmada ise; kanser nedeniyle ameliyat edilen hastalarla karşılaştırıldığında transuretral rezeksiyon ve inkontinans cerrahisi sonrası VTE gelişme ihtimalinin çok daha düşük olduğu bildirilmiştir (8). Transuretral girişimlerde anestezi süresinin 2 saatin üzerinde olması, hasta yaşının $60^{\prime}$ ınüzerinde olması, DVT-PE öyküsünün olması ve postoperatif 4 günün üzerinde yatış süresi risk faktörleri olarak belirlenmiştir (7).

\section{Laparoskopik Cerrahilerde VTE}

Laparoskopik olarak uygulanan cerrahiler sonrasında da; en az açık ameliyatlar kadar DVT ve PE gelişimi görülmektedir. Laparoskopik cerrahiler arasından en fazla DVT ve PE açısından riskli olduğu düşünülen operasyon tekniği radikal prostatektomi'dir. Bu konuda, Tyson ve ark.'ları tarafından son dönemde yapılan bir çalışmada, laparoskopik ve açık radikal prostatektomi uygulanan hastalar DVT gelişme riski açısından karşılaştırılmış, her iki grupta eşit (yaklaşık olarak $\% 0.5$ ) olarak bulunmuştur. PE riski ise açık cerrahi grubunda $\% 0.8$, laparoskopik teknik grubunda ise $\% 0.4$ olarak bildirilmiştir (p>0.05) (6). Diğer taraftan, Secin ve ark.'larının yayınladığı çok merkezli, 5.951 hasta ile yapılan bir çalışmada, laparoskopik veya robot yardımlı prostatektomi sonrası DVT ve PE gelissme oranları sirasıyla $\% 0.5$ ve $\% 0.2$ olarak bildirilmiştir. Hastalarda DVT öyküsünün olması, mevcut sigara içimi, reeksplorasyon, uzun yatış süresi, uzamış operasyon zamanı ve prostat volümünün $100 \mathrm{cc}$ nin üzerinde olması VTE gelişimi için risk faktörleri olarak bildirilmiştir (21). Bu hali ile genel olarak laparoskopik tekniklerin başta radikal prostatektomi olmak üzere DVT ve PE riskini arttırmadığı söylenebilir.

\section{İnontinans Cerrahisinde VTE}

İnkontinans cerrahisi yapılan hastalarda VTE gelişimine diğer ürolojik prosedürlere göre daha az rastlanmaktadır. Anger ve ark.'larının bu konuya ilişkin çalışmalarında, inkontinans ve prolapsus cerrahileri uygulanan hastaların 3 aylık takiplerinde VTE gelişime riskini \%1.3 olarak bildirmişlerdir. Sadece sling uygulanan hastalarda bu oran \%0.9, sling ve prolapsus birlikte uygulananlarda $\% 2.2$ olarak bildirilmiştir. Aynı hastaların 1 yıllık takibi sonucunda ise VTE oranı \%24 olarak rapor edilmiştir (5). Diğer taraftan, pelvik organ prolapsusu nedeniyle laparoskopik kolpopeksi operasyonundan sonra VTE bildirilmemiştir.

\section{Klinik ve Tanı}

Cerrahi sonrası gelişen VTE perioperatif dönemden 1 yıla kadar geniş bir zaman aralığında gelişebilir. Tyson ve ark.'ları ameliyat sonrası bir ay takip ettikleri hastalarda ortalama VTE gelişme zamanını 11 gün olarak bildirmişlerdir (6).

DVT klinik olarak etkilenen ekstremitede ağrı, şişme ve kızarıklık olarak kendini gösterir. Tanıda hızlı, ucuz ve invaziv olmayan yöntemlerden ultrasonografi ve serum D-Dimer analizi kullanılabilir. Venografi tanı koymada en yüksek sensitivite ve spesifiteye sahip olmasına rağmen, invaziv oluşu kullanımını kısıtlamıştır (22).

Ameliyat sonrası hastada görülen beklenmeyen ateş, taşikardi, dispne, takipne, göğüs ağrısı ve şok gibi semptomlar pulmoner emboli açısından cerrahı şüphelendirmelidir (23). Elektrokardiyografi, arter kan gazı, D-Dimer ve ventilasyonperfüzyon sintigrafisi klinik tanıyı koymada yardımcı olur. Ancak PE tanisinin konmasinda pulmoner anjiografi altın standarttır (24).

\section{Tedavi ve Profilaksi}

VTE'ye yönelik tedavi ve profilaksi uygulamaları; mekanik tedaviler (dereceli baskı çorapları, aralıklı hava kompresyon cihazları) ve farmakolojik tedaviler (düşük doz fraksiyone olmayan heparin ve düşük moleküler ağırlıklı heparin) olarak ikiye ayrılmıştır. Antitrombotik ve trombolitik tedavi ile ilgili American College of Chest Physicians'in (ACCP)

Tablo 1: Profilaksi olmadan cerrahi hastalarda tromboembolizm risk dereceleri

\begin{tabular}{|c|c|c|c|c|}
\hline Risk derecesi & DVT & Proksimal DVT & Klinik PE & Ölümcül PE \\
\hline $\begin{array}{l}\text { Düşük risk } \\
\text {-Risk faktörü olmayan } 40 \text { yaş altı minör } \\
\text { cerrahi hastaları }\end{array}$ & $\% 2$ & $\% 0.4$ & $\% 0.2$ & $\% 0.01$ \\
\hline $\begin{array}{l}\text { Orta risk } \\
\text {-Risk faktörü olan minör cerrahi hastaları } \\
\text {-Risk faktörü olmayan 40-60 yaş arası cerrahi } \\
\text { hastaları }\end{array}$ & $\% 10-20$ & $\% 2-4$ & $\% 1-2$ & $\% 0.1-0.4$ \\
\hline $\begin{array}{l}\text { Yüksek risk } \\
\text {-60 yaş üstü veya ek risk faktörü bulunan } \\
\text { hastalar (VTE öyküsü, kanser) }\end{array}$ & $\% 20-40$ & $\% 4-8$ & $\% 2-4$ & $\% 0.4-1$ \\
\hline $\begin{array}{l}\text { Çok yüksek risk } \\
\text {-Birden fazla risk faktörü bulunan cerrahi hastalar } \\
\text { (yaş>40, VTE öyküsü, kanser) } \\
\text {-Kalça ve diz artroplasti, kalça kırı̆̆ı amelivatları }\end{array}$ & $\% 40-80$ & $\% 10-20$ & $\% 4-10$ & $\% 0.2-5$ \\
\hline
\end{tabular}

DVT: Derin ven trombozu, PE: pulmoner emboli, VTE: venöz tromboembolizm öyküsü 
düzenlediği 7. Konferans'da cerrahi işlem yapılacak hastalara kişiye özel, medikal ve cerrahiyle ilgili risk faktörlerine göre düşük, orta, yüksek ve çok yüksek olarak risk gruplarını içeren bir risk sınıflandırması yapılmasını önermişlerdir (25) (Tablo 1).

American Urological Association (AUA ) ise risk siniflandırmasına göre, düşük riskli ve minor işlemlerde erken mobilizasyon, orta riskli grupta mekanik veya farmakolojik profilaksi, yüksek riskli grupta hem mekanik hem de farkmakolojik profilaksinin yapılması ve kanama açısından riskli grubun dikkatli şekilde değerlendirilmesi önerilmiştir (25).

Hastalarda profilaksi ile birlikte erken mobilizasyon ve perioperatif baskı çoraplarının kullanılması gibi basit önlemlerle hastalarda VTE gelişimi ve buna bağlı PE gelişimi olasılığı azalmaktadır (26).

Antikoagülan ajan araştırmaları yoğun olarak devam etmekte ve özellikle Faktör Xa'yı hedef alan ajanlar yoğun bir şekilde araştırılmaktadır. Araştırmalar sonucu Faktör Xa'yı hedef alan Apixaban, Edoxaban, Rivaroxaban; Faktör IIa'yı hedef alan Dabigatran Etexilat'ın VTE önlenmesinde güvenilir ve etkili olduğu gösterilmiştir (28).

Ameliyat sonrası DVT gelişen tüm hastaların tedavi edilmesi şarttır. Çünkü tedavi edilmeyen proksimal alt ekstremite DVT sonrasında \%50 oranında PE gelişme riski vardır (28). Tedavide düşük doz fraksiyone olmayan heparin (iv), düşük moleküler ağırlıklı heparin ve fondaparinux (sc) veya warfarin (oral) kullanılabilir (29). PE tedavisi de aynı ajanlar ile iv, sc veya oral olarak risk gruplarına göre 6-12 ay kadar süre ile uygulanmalıdır (30).

\section{Sonuç}

Perioperatif ve postoperatif mortalite ve morbiditenin önlenebilir nedenlerinden biri olan venöz tromboembolizm, ürolojik cerrahiler sonrasında da dikkate değer oranlarda görülmektedir. Hastalara operasyon öncesinde profilaksi yapılması ve yakın takip, tromboemboliye bağlı mortalite ve morbiditenin azalmasını sağlayacaktır. Bu nedenle özellikle tüm büyük ve komplike ürolojik girişimlerde tromboprofilaksi de cerrahinin bir parçası olarak düşünülmeli ve planlanmalıdır.

\section{Kaynaklar}

1. Geerts WH, Pineo GF, Heit JA, Bergqvist D, Lassen MR, Colwell CW, Ray JG. Prevention of Venous Thromboembolism: The Seventh ACCP Conference on Antithrombotic and Thrombolytic Therapy Chest 126: 338-400, 2004.

2. Kibel AS, Loughlin KR. Pathogenesis and prophylaxis of postoperative thromboembolic disease in urological pelvic surgery. J Urology 153:1763-1774, 1995.

3. Bates SM, Ginsberg JS. Treatment of Deep-Vein Thrombosis. N Engl J Med 351:268-277, 2004.

4. Bell CRW, Murdock PJA, Pasi KJ, Morgan RJ. Thrombotic risk factors associated with transuretral prostatectomy. Br J Urol Int 83: 984-9, 1999

5. Anger JT, Weinberg AE, Gore JL, Wang Q, Pashos CL, Leonardi MJ, Rodríguez LV, Litwin MS. Thromboembolıc complications of Sling surgery for stress urinary incontinence among female medicare beneficiaries. Urology 74(6): 1223-1226, 2009.
6. Tyson MD, Castle EP, Humphreys MR, Andrews PE. Venous Thromboembolism after Urologic Surgery. J Urol. 2014 Mar 1.

7. Scarpa RM, Carrieri G, Gussoni G, Tubaro A, Conti G, Pagliarulo V, Mirone V, De Lisa A, Fiaccavento G, Cormio L, Bonizzoni E, Agnelli G; @RISTOS Study Group. Clinically overt venous thromboembolism after urologic cancer surgery: results from the @RISTOS Study. Eur Urol 51(1):130-5, 2007.

8. J Dyer, S Wyke, C Lynch. Hospital Episode Statistics data analysis of postoperative venous thromboembolus in patients undergoing urological surgery: a review of 126,891 cases. Ann R Coll Surg Engl 2013; 95: 65-69 (X)

9. White $\mathrm{RH}, \mathrm{Zhou} \mathrm{H}$, Romano PS. Incidence of symptomatic venous thromboembolism after different elective or urgent surgical procedures. Thromb Haemost 90(3):44655, 2003.

10. Prins $\mathrm{MH}$, Hettiarachchi RJ, Lensing AW, Hirsch J. Newly diagnosed malignancy in patients with venous thromboembolism. Search or wait and see? Thromb Haemost 78:121-125, 1997.

11. Donati MB, Poggi A. Malignancy and haemostasis.Br J Haematol 44:173-182, 1980.

12. Rosario DJ, Becker M, Anderson JB. The changing pattern of mortality and morbidity from radical cystectomy. BJU Int 85:427-430, 2000.

13. Rice KR, Brassell SA, McLeod DG. Venous thromboembolism in urologic surgery: prophylaxis, diagnosis and treatment. Rev Urol 12(2/3): 111-24, 2010.

14. Middleton AW Jr. Pelvic lymphadenectomy with modified radical retropubic prostatectomy as a single operation: technique used and results in 50 consecutive cases. J Urol 125:353-356, 1981.

15. Dillioglugil O, Leibman BD, Leibman NS, et al. Risk factors for complications and morbidity after radical retropubic prostatectomy. J Urol 157:1760-1767, 1997.

16. Koya MP, Manoharan M, Kim SS, Soloway MS. Venous thromboembolism in radical prostatectomy: is heparinoid prophylaxis warranted? BJU Int 96:10191021, 2005.

17. Leibovitch I, Foster RS, Wass JL, et al. Color Doppler flow imaging for deep venous thrombosis screening in patients undergoing pelvic lymphadenectomy and radical retropubic prostatectomy for prostatic carcinoma. J Urol 153:1866-1869, 1995.

18. Sieber PR, Rommel FM, Agusta VE, et al. Is heparin contraindicated in pelvic lymphadenectomy and radical prostatectomy? J Urol 158: 869-871, 1997.

19. Pettus JA, Eggener SE, Shabsigh A, et al. Perioperative clinical thromboembolic events after radical or partial nephrectomy. Urology 68:988-992, 2006.

20. Donat R, Mancey-Jones B. Incidence of thromboembolism after transurethral resection of the prostate (TURP) - a study on TED stocking prophylaxis and literature review. Scand J Urol Nephrol 36:119-123, 2002.

21. Secin FP, Jiborn T, Bjartell AS, et al. Multiinstitutional study of symptomatic deep venous thrombosis and pulmonary embolism in prostate cancer patients undergoing laparoscopic or robotassisted laparoscopic radical prostatectomy. Eur Urol 53: 134-145, 2008.

22. Cronan JJ. Venous thromboembolic disease: therole of US. Radiology 186:619-630, 1993. 
23. Kasper W, Geibel A, Tiede N, Just H. Patients foramen ovale in patients with hemodynamically significant pulmoner embolism. Lancet 340: 561-4, 1992.

24. Stein PD, Fowler SE, Goodman LR, et al. Multidetector computed tomography for acute pulmonary embolism. N Engl J Med 354:2317-2327, 2006.

25. Büller HR, Agnelli G, Hull RD, et al. Antithrombotic therapy for venous thromboembolic disease: the Seventh ACCP Conference on Antithrombotic and Thrombolytic Therapy Chest 126 (3):401-428, 2004.

26. G Agnelli. Prevention of Venous Thromboembolism in Surgical Patients. Circulation. 2004;110:4-12 (Z)

27. Galanis T1, Keiffer G2, MerliG. The new oral anticoagulants for the treatment of venous thromboembolism: a new paradigm shift in antithrombotic therapy. Curr Ther Res Clin Exp. 2014 Sep 28;76:76-83. (Y)

28. Alpert JS, Dalen JE. Epidemiology and natural history of venous thromboembolism. Prog Cardiovasc Dis 36: 417422, 1994.

29. Bergqvist D, Jönsson B. Cost-effectiveness of prolonged administration of a low molecular weight heparin for the prevention of deep venous thrombosis following total hip replacement Value Health 2: 288-294, 1999.

30. Optimum duration of anticoagulation for deep-vein thrombosis and pulmonary embolism. Research Committee of the British Thoracic Society. Lancet 340: 873-876, 1992.

Yazışma Adresi:

Metin Öztürk

Haydarpaşa Ĕ̆itim ve Araştırma Hastanesi,

Tibbiye Cad. No: 40, Üsküdar

Tel: +902165537251

e-mail:drmetinozturk@gmail.com 